\title{
Techniques of the Translation of Culture
}

\author{
Xiao Geng \\ Qingdao University of Science \& Technology, Qingdao, China
}

\begin{abstract}
This article discusses the basic principle of the translation of the culture and explores some techniques of the translation of culture. It also studies the impact of cultural differences on translation in several aspects. Language is a social behavior that reflects culture. Being ignorant of the target language culture, we would be a failure in translating, thus translating a langue into another foreign language necessarily involves culture integration. It is not enough to be aware of the importance of integrating culture into translating. To integrate culture into foreign language translating, it is necessary to be clear about the cultural differences between the foreign language and the native language and how the target-language-culture is reflected in its language.
\end{abstract}

Index Terms - techniques, translation, cultural differences

\section{INTRODUCTION}

The translation of culture is more difficult to master than article translation. Sometimes even a word and a phrase takes much time to establish in translation. Translation of words and phrase should obey thee translation criteria like faithfulness, expressiveness and elegance. These standards are useful to the translation of culture.

But sometimes we cannot translate words and phrases only according to the above stands. There is one more important thing we should not neglect: culture influence upon the translation of words and phrases. There are several ways of translation, such as pure translation, pure semantic translation etc. Culture factor is an important part we should consider. So in the translating, culture should be integrated in translating.

Cultural differences are a social phenomenon. Translating culture does not mean making one culture conform to the other, and cultivate the cultural sensitivity of translating. As has been mentioned before, the lady got angry because Calvin made sudden visits without making an appointment ahead of time. It shows two completely different cultural attitudes toward making a visit. There are many such examples. Different cultures take different attitudes towards the scope and place of making an apology.

It can be seen that translation is indeed in the broad context of research.How to find the best way of translation on the premise of foreign culture. What's the basic principle of the translation of culture? The author talks about a little shallow opinion about these questions.

Translation is one kind of action by which different nations can communicate thought and culture. It realizes by the transform of different languages. Many aspects impact this kind of translation. Here we study the techniques of the Translation of Culture.

Language is a social behavior that reflects culture. Being ignorant of the target language culture, we would be a failure in our communication, thus teaching English in China as a foreign language necessarily involves culture integration.

\section{CUltural InfluenCE ON LANGUAGE}

Following the definitions of sociologists and anthropologists, the term "culture" refers to the total patterns of beliefs, customs, institutions, objects and techniques that characterize the life of a human community. "Culture consists of all the shared products of human society."(Smith, 1987) This means not only such material things as cities, organizations and schools, but also non-material things such as ideas, customs, family patterns, and languages. Putting it simply, culture refers to the entire way of life of a society, "the ways of a people." Members of a particular culture have certain things in common, a certain way of life, a certain way of behavior. What the share includes certain values and beliefs, certain customs, perhaps certain gestures or certain foods. They may also share distinctive artifacts, a distinctive art, a distinctive music and a body of literature and folk stories.

Language is a part of culture and plays a very important role in it. Some social scientists consider it the keystone of culture. Without language, they maintain, culture would not be possible. And every social institution is maintained by language; law, religion, government, education, and the family are all set in place and carried out with language. People use language to reveal or conceal their personal identities, their characters, and their background, often wholly unconscious that they are doing so.

On the other hand, language is influenced and shaped by culture; it reflects culture. In the broadest sense, language is the symbolic representation of a people, and it comprises their historical and cultural backgrounds as well as their approach to life and their ways of living and thinking. Cultural patterns, customs and ways of life are expressed in language; culture specific worldviews are reflected in language. 
As language and culture are inseparable, a newborn baby learns his mother tongue and its culture at the same time. When children are growing up, they learn how to do within their own culture. They get to know what languages and beavers are appropriate in a given situation, how to interact the actions happening around them. At the same time, they get to learn to communicate with others with their language. Language and culture are, of course, inextricably linked; so learning a language means learning culture. For example, when we grow up in Chinese cultures we learn to say "Can I have a drink?" rather than "Give me a drink"; we don't address our brothers and sisters by their first names except they are younger than us; we learn to say "thank you" when accepting something. In other words, in learning how to speak, we must not only master the vocabulary and grammar of a certain language, we must also absorb the social rules that govern how we should use vocabulary and grammar in concrete situations. The social rules are sometime the cultural factors. Everyone knows that cultures differ from one another, that every culture is unique. Since cultures are diverse, so are the languages. Cultural influence on language embodies mainly in two aspects: cultural similarities cause language similarities, and cultural differences cause language differences.

Every nation has its own way of viewing the universe, and each develops from its own premises a coherent set of rules, which will be handed down from generation to generation. Gradually, they are accepted as the essential part in people's life. This is the formation of culture. Since the social background and geographic situations are different from nation to nation or even from place to place in the same country, cultures in different nations have more differences' influence on language. So, more emphasis will be put on cultural differences' influence on language, though there are cultural similarities between China and western countries. Cultural differences will be discussed in details, which cause language differences. Geographic situations, social backgrounds, and cultural patterns all belong to cultures.

\section{A. Geographic Situations'Influence on Language}

England has a peculiar meteorological condition. In no country other than England, it has been said that one can experience four seasons in the course of a single day! Day may begin with a balmy spring morning; about an hour later, there may be black clouds appearing from some place and the rain may be pouring down. At noon it may be wintry with the temperature down by about eight degrees centigrade. After that, about in the late afternoon, it will be clear up, the sun will begin to shine, and for an hour or two before darkness falls, it maybe like a summer day.

In England, one can experience almost every kind of weather except the most extreme. You never can be sure what type of weather condition will appear. We not only do get several different sorts of weather in one day, but also we may experience the spell of winter in summer and vice-versa. The uncertainty about the weather has had a definite influence on the Englishman's language. When they meet each other, after a "Hi" or "Hello", they like to talk about the weather, for example, they often say: “It's a fine day, isn't it?" But we Chinese like to ask food and places, because to us Chinese where our friends are going and whether they have eaten is about our concern. So we often start our conversation or greeting by enquiring such things.

The geographic situations' influence on language can also be testified by the following example. In Chinese opinion, the east wind stands for warmness, spring and also the beautiful things. The famous poet Li Shangyin has a famous poetry entitled "wuti" in which there is a sentence use east wind. In Chinese, the east wind should be the messenger of urging the flowers to blossom. This poem used to be translated as a good exemplification

The Englishman finds it hard to understand. Because according to England's location, in their eyes, the east wind should be bitter cold wind while the west wind symbolizes warmness. John Mansfield's famous poem "Ode to the West Wind" is a good example in point.

The different understanding towards west winds and east winds between Westerners and Chinese is caused by the influences of culture on language. According to England's location, west wind can bring warmness to them. So, in English, they use west wind to stand for the beautiful things, while in China, we use east winds to stand for beautiful things.

\section{B. Social Background's Influence on Language}

China is a country with a history of five thousand years. And Confucianism plays an important part in Chinese history. The Chinese distinguish their relative relationships seriously. This is caused by the feudalism culture. In this culture, any social relationship must be stipulated by the relative titles. No matter it is at funeral or wedding or when one inherits the heritage, it must also be dealt with according to relative trees. This strict distinction causes the complexity of relative titles in Chinese. In traditional Chinese family, there are usually a large number of people, including uncles, aunts, brothers and sisters, etc. So they tell elder brother from younger brother and also tell elder sister from younger sister. But in a traditional English family, which is usually a nuclear family, only the parents and their children live together .So they don't tell father's younger brother from father's older brother, not because they can't do so, but because on most occasions, they don't have to. The feudal culture enriches the Chinese vocabulary, and causes Chinese have more words about relative titles. And also because of the influence of western culture, English doesn't have many words about relative titles.

China used to be an agricultural nation. Agriculture plays a very important part in the daily life of Chinese people. This feature is often reflected in our Chinese language. So there are many idioms and expressions related to agriculture in Chinese, These all attribute to the influence of Chinese culture.

The history of Britain is a history of invasion. Britain invaded many countries in the history, and it used to be called 
"The sun never setting empire". The Britain once defeated the "Invincible Fleet" of Spain on the sea in Elizabeth age and became the imperialist power in the world at that time. So there are some English phrases related to sea and fishing such as "be all at sea", "know the ropes", while the language related to agriculture is rare.

One important factor to maintain harmonious relationships with others is to be courteous with others. There is a little difference in the usage of polite words between Chinese and English. Though it is true that in every culture, people use polite language to be courteous, when and what to say make differences. It can be very impolite not to add the polite words when one is supposed to. Take "thank you" for example.

In Chinese culture people will only say "xiexie", the Chinese equivalent of "thank you". When they get help from others, and if it is only a minor help, people always omit that. However, in western countries, it is used in a much broader context. Except from getting help, they use it in occasions like shopping, answering a call, or just for the attendance in a party. It sometimes puzzles the Chinese when a westerner says "thank you" after we sell things to them. For we think it should be we who need to say that, and we sometimes respond that with "thank me for what". This kind of misunderstanding is due to the ignorance of other's culture. In fact, "thank you" to westerners does not only show the gratitude in our understanding, rather, it has been used as a custom and of course, they sometimes are prepared for the others to say that. If we treat this situation the same way as we Chinese do, it will not be very polite. There is another point regarding to the difference in using "thank you".

We Chinese will not use it or use fewer as a sign of intimate relations and just bear the gratitude in mind. For Chinese are more introverted in showing feelings. However, in western countries, people are more open in showing feelings, so they will not omit that even to their parents. This difference in the use of polite words is caused by the difference of culture.

\section{Cultural Pattern's Influence on Language}

Cultural patterns address the manner in which a culture orients itself to activities, social relations, the self, and the world. In studying cultural differences, many researchers cite the concept of "cultural patterns". Larry presents that there are five primary differences in cultural patterns. I will also discuss cultural patterns' influence on language from these five aspects.

\section{Preserving the Culture Feature in the Source Language}

\section{A. Using Literal Translation, Liberal Translation and Explanatory Notes Correctly}

If the literal translation, liberal translation and explanatory notes are correct, the culture of the source language will be expressed better. In the following text, some examples will be given in order to make readers understand these skills better.

Some English idiom is from the figure of Bible. If the literal translation and explanatory notes are used together, the metaphoric meaning will be expressed vividly. For example: as old as Methuselah, as rich as Jew, as wise as Solomon. Methuselah is the son of Yinno in Bible. He had lived for 969 years. The ancient Jew is very rich and so the Jew is the symbol of rich man. Solomon who is famous for his wisdom is the king of the ancient Israel.

Sometimes the literal translation may make the original text vivid and supplement the Chinese vocabulary. This kind skill is used frequently in political term. for example: Lame duck - the officer who is relieved of his office doesn't win in the re-election. Dark horse-the candidate who is unpopular with people defeats the others we unexpected. This way of translation should be adopted on the premise of the accepting by Chinese.

We rise that the foreign sentiment should be stressed in the translation. It is the so-called foreign flavor, which refers to preserving the culture features of foreign countries in the source language. Do not make the English have the Chinese color. The correct way of translation is better. For example: as gentle as lamb, as gay as a lark. In this way it not only expresses the image of the original text, but also increases the foreign sentiment in the translation. Going after the foreign flavor and image painstakingly may have an exact opposite effect.

\section{B. Avoiding Put Forcedly the National and Local Color into the Translation}

There is something in English that only exists in the special culture. They cannot be translated into Chinese style. This is so-called the cultural conflict. Such as yu mi zhi xiang, It is proper to be translated into the rich place. "When Greek meets Greek, then comes the tug of war." The proverb describes the indomitable resistance of old Greek. Now, it describes the fierce fight between two warriors or two brave armies. Some in Chinese history is not in Britain's. So it cannot be found in the translation.

\section{Dealing with the Rustic Flavor in the Foreign Flavor}

When English words and phrases are transformed into Chinese, not only the foreign flavor should be preserved, but also should remain the rustic flavor in it including those substandard English phrases and slang. This kind expression can exaggerate individual characters, the level of knowledge and the social position of the person.

"I keep it from her after I heard on it," said Mr. Peggotty, "goings-on nigh a year. We were living then in a solitary place, but among the most beautiful trees." There are many mistakes in the words of Mr. Peggotty in original text, which shows that the education he accepts is little. He is not a person in the upper class. The translation expresses is 
according to the facts. The translation should faith to the original text though this kind of translation is clear and coherent. Or the rustic flavor is missing. It is conform to the tone of Peggotty.(Heping,1998,P9)

About the technique of translation, limited by the paper, the author discussed superficially the above little opinion.

\section{The IMPACT OF CUltural DifFERENCES ON TRANSLATION}

In order to translate well besides the techniques, some impacts of cultural differences should be taken attention to.

\section{A. The Impact of Social Culture}

There is a great difference in the use of the words, the way of thought and the habit of expression in English and Chinese. The translation should focus on the thought and the culture communication. This condition can be found in some examples.

One company invites some foreign experts to a dinner party. Although there are many wonderful foods and wine, the host stands up and says: "Please forgive me because the dishes are not good." These words are very suited to Chinese, but the foreigners will be confused. They don't understand why not receive them with good food. Because of the different social culture, they have some embarrassment.

\section{B. The Impact of Custom}

The typical custom difference between the English and Chinese are the connotations of some words for instance. Both the Chinese and English languages contain a lot of words denoting animals, plants and seasons. However, because of different history and culture, the connotations of these words in one language do not necessarily coincide with those in the others.

In the view of Chinese, goat is a commendatory term. When British see the word, they will connect it with lecher.

Some words denoting plants have deep metaphoric meanings in China. Willow is often compared to prostitute, frivolous and ruthless woman and brothel. Willow in English was the symbol of miserable fate of Ophelia; she had just sung the song of willow before she died.

In China, when people talk about autumn, they always think of the words "sad, discourage, distressed and grievous." When autumn comes and the cool wind blows, people stepping on the fallen leaves, they feel very depressed. The meaning of autumn in English is opposite. They feel comfortable and pleasant.

\section{The Impact of System, Faith and World View}

In tradition, when building house or tomb, Chinese people believe that the location has an influence on the fortune of a family. The idea doesn't exist in European. In the European culture, when a person dies, he will be buried in the tomb of the church. Although they also choose direction of the building when they build house, it is for the building itself. Chinese people stress to choose lucky day, when they want to do something import. In many areas, people inhibit the odd days. They always choose the even-number days to get married. In the view of European, either the odd-number days or the even-number days are the same. But they inhibit the number 13. They believe the number is not auspicious. Just like the European doesn't understand the meaning of the odd-numbered days and the even-numbered days, the auspicious number is 13 .

\section{Being Extensive the Knowledge of Different Culture}

The culture of each nation is one part of the developing of the society. It is easy to deal with the university in translation. But each nation has different culture. There are many differences in religious, custom and social culture excepting in the world view. In order to communicate the differences, the extensive knowledge is required. The abundant culture knowledge is the premise of doing the translation well.

\section{Globalization and ReCOGNition of Some Translation}

\section{A. Loanwords and Globalization}

In the recent ten years, the contact between China and other countries become more and more frequent. More and more translation works appear in many fields, such as in economy, politics, trade and tourism. Culture communication is becoming more and more frequent. Different culture phenomenon is familiar to different people. There are some words and phrases being accepted by other cultures and popular in other cultures. Cases in point are qigong, wushu, kungfu, jiaozi, etc. There words have been accepted by English speaking countries. And "kelong", "jiyin", “coco" are popular with Chinese people. Some words like "CD", "VCD", "OK" and "E-mail" are used directly instead of being translated into Chinese.

\section{B. Recognition of Some Translation like "Telephone"}

In 1930s, "telephone" was translated into "delufeng" and in 1950s "laser" into "laisai". At that time, people did not know what they were. As years passed, people know more about these things and change their names into "dianhua" and "jiguang". "xiangbin" is the transliteration of Shampagne where the wine is made in France. The translator is intelligent to combine the euphony with the mellowness of the wine and hospitality of welcoming the guest. All these 
examples show the culture influence upon the translation of words and phrases.

\section{CONCLUSION}

"Leaning a language is a kind of learning the culture and habit of the country where the language is spoken." Translation, we should learn the different cultures, including its tradition, habits, social customs, morals and so on. Culture exerts strong influence on language. In the translation of words and phrases, culture background is essential. A translator without understanding the culture cannot translate well. We should take the culture factor as an important part in translation and translate words and phrases according to the rules of translation so as to get rid of unreasonable translation.

Cultural difference has great impact on translation .The premise of doing well translation is having extensive knowledge about culture .We should gasp firmly the basic principle of the translation of culture, master the technique and skills of it and the deep connotation of culture, preserve the culture feature of foreign country in the source language. Don't make the English have the color of China.

\section{REFERENCES}

[1] Keping. (1988). No Match between Cultural Difference and Semantic Translation. Chinese Translations Journal 1, 9-10.

[2] Kong Huiyi. (1999). Translation literature and Culture. Beijing: The Press of Beijing University.

[3] Liu Li. (1998). From the Cultural View to See the Language Teaching. Shanghai: Shanghai Foreign Language Education Press.

[4] Mark J. Smith. (1987) Culture: Reinventing the Social Science. Open University Press.

[5] Wang Wenhua. (2000). Differences and Translation. Changsha: The Press of Zhongnan University.

[6] Wang Bingqian. (1995). The Science of Cultural Translation. Tianjin: The Press of Nankai University.

[7] Wang Kefei. (1997). The History of Translation Culture. Shanghai: Shanghai Foreign Language Education Press.

[8] Yu Dequan. (1998). Foreign Languages Research. Beijing: The Press of World Languages in China.

Xiao Geng was born in Weihai, china in 1970. She received her M.A. degree in Linguistics from Qufu Normal University, China in 2004.

She is currently an associate professor in the school of Foreign Languages, Qingdao University of Science and Technology, Qingdao, China. Her research interests include teaching methods and the Second Language Acquisition.

Professor Geng is a member of the Institute of Linguistic Study. 